\title{
Prognoses of different pathological subtypes of colorectal cancer at different stages: A population-based retrospective cohort study
}

\author{
Xiaoli Wu ${ }^{1+}$, Han Lin ${ }^{2+}$ and Shaotang $\mathrm{Li}^{3^{*}}$ (D)
}

\begin{abstract}
Background: Whether the prognoses of different pathological subtypes of colorectal cancer (CRC) at different stages are distinct is unclear.

Methods: We extracted data on all cases of CRC from the Surveillance, Epidemiology, and End Results database between 2004 and 2015. The incidence of different pathological subtypes, clinical characteristics, and five-year overall survival (OS) and cause-specific survival (CSS) were analyzed.

Results: A total of 384,996 cases diagnosed as adenocarcinoma (AC), mucinous adenocarcinoma (MAC), and signet ring cell carcinoma (SRCC) were included in this analysis. Compared with AC, MAC and SRCC were more likely to reach T4, N2, M1, stages III and IV, and grades III and IV, and patients were generally of a younger age $(P<0.001)$. Compared with those with AC, patients with MAC and SRCC showed poorer OS (50.6 and $26.8 \%$ vs. 60.2\%, $P<.001$ ), with corresponding HR values of $1.238(95 \% \mathrm{Cl}, 1.213-1.263, P<.001)$ and $1.592(95 \% \mathrm{Cl}, 1.558-1.627, P<.001)$, respectively. The MAC and SRCC groups also showed poorer overall CCS (60.9 and $32.5 \%$ vs. $67.8 \%, P<.001$ ), with corresponding HR values of $1.271(95 \% \mathrm{Cl}, 1.242-1.302, P<.001)$ and $1.724(95 \% \mathrm{Cl}, 1.685-1.765, P<.001)$, respectively. Compared with patients with $A C$, those with MAC showed poor OS at every stage and poor CSS at every stage except stage II $(P<.05)$, while patients with SRCC revealed poor OS and CSS at every stage except stage $0(\mathrm{P}<.05)$.

Conclusions: Patients of different pathological subtypes minimally differed at early stages. However, patients with AC have significantly better prognoses in advanced CRC (stages III and IV) than those with MAC or SRCC. Distinct treatment strategies should be applied depending on a particular histological subtype in advanced CRC.
\end{abstract}

Keywords: Adenocarcinoma, Colorectal cancer, Mucinous adenocarcinoma, Prognosis, Signet ring cell carcinoma

\section{Background}

CRC is the third most common malignancy and the second most common cause of death worldwide. About 1.4 million new cases are reported every year [1]. CRC is a significantly heterogeneous tumor with three major histological subtypes: $\mathrm{AC}$, mucinous $\mathrm{AC}$ (MAC), and signet ring cell carcinoma (SRCC). Whereas typical ACs

\footnotetext{
*Correspondence: lishaotang163@163.com

${ }^{+}$Xiaoli Wu and Han Lin contributed equally to this work.

${ }^{3}$ Department of Colorectal Surgery, the First Affiliated Hospital of Wenzhou

Medical University, Wenzhou, Zhejiang, People's Republic of China

Full list of author information is available at the end of the article
}

are the most common cancers of the colorectum, the two other pathological subtypes are rare and have characteristics distinct from those of AC, including a younger age of onset, more advanced stage, and increased likelihood of lymph node and peritoneal metastases upon presentation [2-6]. Although SRCC is widely believed to have poor prognosis $[3,5,7]$, the prognosis of MAC remains unclear. A number of studies have demonstrated poorer outcomes in patients with MAC patients $[8,9]$, whereas other researchers have found different results $[10,11]$. Several articles have demonstrated whether the prognoses of different histologic

(c) The Author(s). 2019 Open Access This article is distributed under the terms of the Creative Commons Attribution 4.0 International License (http://creativecommons.org/licenses/by/4.0/), which permits unrestricted use, distribution, and 
subtypes of colorectal cancer at different stages are distinct, but the results are unclear. Thus, the present study aimed to analyze the incidence of different pathological subtypes, clinical characteristics, and prognoses of different histologic subtypes of colorectal cancer at different stages.

\section{Methods}

\section{Population selection}

This study investigates the incidence rate, clinical characteristics, and oncological outcomes of patients with CRC. The data were extracted from the Surveillance, Epidemiology, and End Results (SEER) database and described in accordance with the items and codes documented by the North American Association of Central Cancer Registries [12]. Patients between 2004 and 2015 were extracted and coded in accordance with the year of diagnosis (Item 390). Tumor site and histology were coded in accordance with the criteria in the third edition of the International Classification of Diseases for Oncology [13]. Colorectal cancers included C18.0-cecum, C18.2-ascending colon, C18.3-hepatic flexure of the colon, C18.4-transverse colon, C18.5-splenic flexure of the colon, C18.6-descending colon, C18.7-sigmoid colon, C188-C189-large intestine, NOS, C19.9-rectosigmoid junction, and C20.9-rectum (Items 522 and 523). Patients who were diagnosed at autopsy or by death certificate only, who had another malignancy before CRC (Item 380), and who had no histologically confirmed cancer (Items 490 and 2180) were excluded from this study. This study was further stated patients with ACs, which were identified by histology codes 8140,8144 , $8210,8211,8220,8221,8255,8260,8261,8262,8263$, mucinous 8480, mucin-producing adenocarcinoma 8481, and signet ring cell carcinoma 8490 (Item 522). Finally, this study was stated patients with clear stages as identified by the DERIVED AJCC-6 STAGE GRP (Item 3000).

\section{Statistical analysis}

Data were analyzed using SAS statistical software (version 9.4; SAS Institute Inc.). Proportions were analyzed by the chi-squared test, and the correlations of each factor with OS and CSS were tested by logistic analysis. OS and CSS were also analyzed by the Kaplan-Meier method and Cox regression analysis.

\section{Results}

\section{Study participants}

This study identified 445,198 patients who were diagnosed with colorectal malignant tumors between 2004 and 2015. After patients with unclear stage were excluded, a total of 399,791 patients were diagnosed with AC, MAC, SRCC, and other pathologies. The distribution of pathological subtypes was as follows: $87.5 \%$ (349,
891 of 399,791$)$ AC, $7.8 \%(30,965$ of 399,791$)$ MAC, $1.0 \%$ (4140 of 399,791) SRCC, and 3.7\% (14,795 of 399, 791) other pathologies. After patients with other pathologies were excluded, 384,996 patients remained in the cohort. Patients without survival time information were excluded from the OS analysis. Finally, 308,163 patients were retained in the cohort. After patients with unknown/missing cause of death were excluded from the CSS analysis, 306,262 patients remained in the study. Figure 1 lists the selection process for participants.

\section{Patients' clinical characteristics}

The patients' clinical characteristics are listed in Table 1. In this study, approximately $90.1 \%(349,891)$ of the patients were diagnosed with AC. Compared with AC, MAC and SRCC were more likely to reach T4 (22.2 and $36.8 \%$ vs. $12.6 \%), \mathrm{N} 2$ (19.7 and $41.0 \%$ vs.13.0\%), M1 (20.3 and $38.5 \%$ vs.19.0\%), stage III ( 32.0 and $39.5 \%$ vs. $25.725 .7 \%$ ), stage IV (20.3 and $38.5 \%$ vs. $19.0 \%$ ), grade III (18.1 and $67.9 \%$ vs. $14.4 \%)$, and grade IV (2.8 and $11.2 \%$ vs. $1.7 \%)$, and patients with these cancers were of a relatively younger age ( $\leq 44$ years, 5.9 and $11.6 \%$ vs. $5.0 \%)$, respectively $(P<0.001)$.

\section{Prognostic factors}

The factors correlated with prognosis (OS and CSS) are listed in Table 2. Logistic analysis demonstrated the following factors associated with poor prognosis: male sex, old age ( $\geq 60$ years), unmarried status, histopathology grades 3 and 4, MAC and SRCC, and stages III and IV $(P<0.001)$. Among these factors, stage classification and pathological subtype were the two most significantly associated with disease prognosis.

\section{Pathological subtypes and prognoses at every stage}

This study performed exploratory analyses to demonstrate the associations of the pathological subtype with OS and CSS. The pathological subtypes were found to be correlated with the prognosis. Compared with patients with $\mathrm{AC}$ at all stages (0-IV), those with MAC and SRCC displayed a poorer OS (50.6 and $26.8 \%$ vs. $60.2 \%$, $P<.001)$, with corresponding HR values of 1.238 (95\% CI, $1.213-1.263, P<.001)$ and 1.592 (95\% CI, $1.558-$ $1.627, P<.001)$, respectively. Similarly, compared with patients with AC, those with MAC and SRCC showed a poor CCS (60.9 and $32.5 \%$ vs. $67.8 \%, P<.001)$, with corresponding $\mathrm{HR}$ values of 1.271 (95\% CI, 1.242-1.302, $P<.001)$ and 1.724 (95\% CI, 1.685-1.765, $P<.001)$, respectively (Tables 3,4$)$. Patients with MAC and SRCC generally showed poor OS and CCS (Figs. 2, 3), although different pathologies resulted in significantly different prognoses (logrank [Mantel-Cox], $P<.001$ ). The median OS and CSS of patients with SRCC were 19 and 23 months, respectively. We further analyzed the 


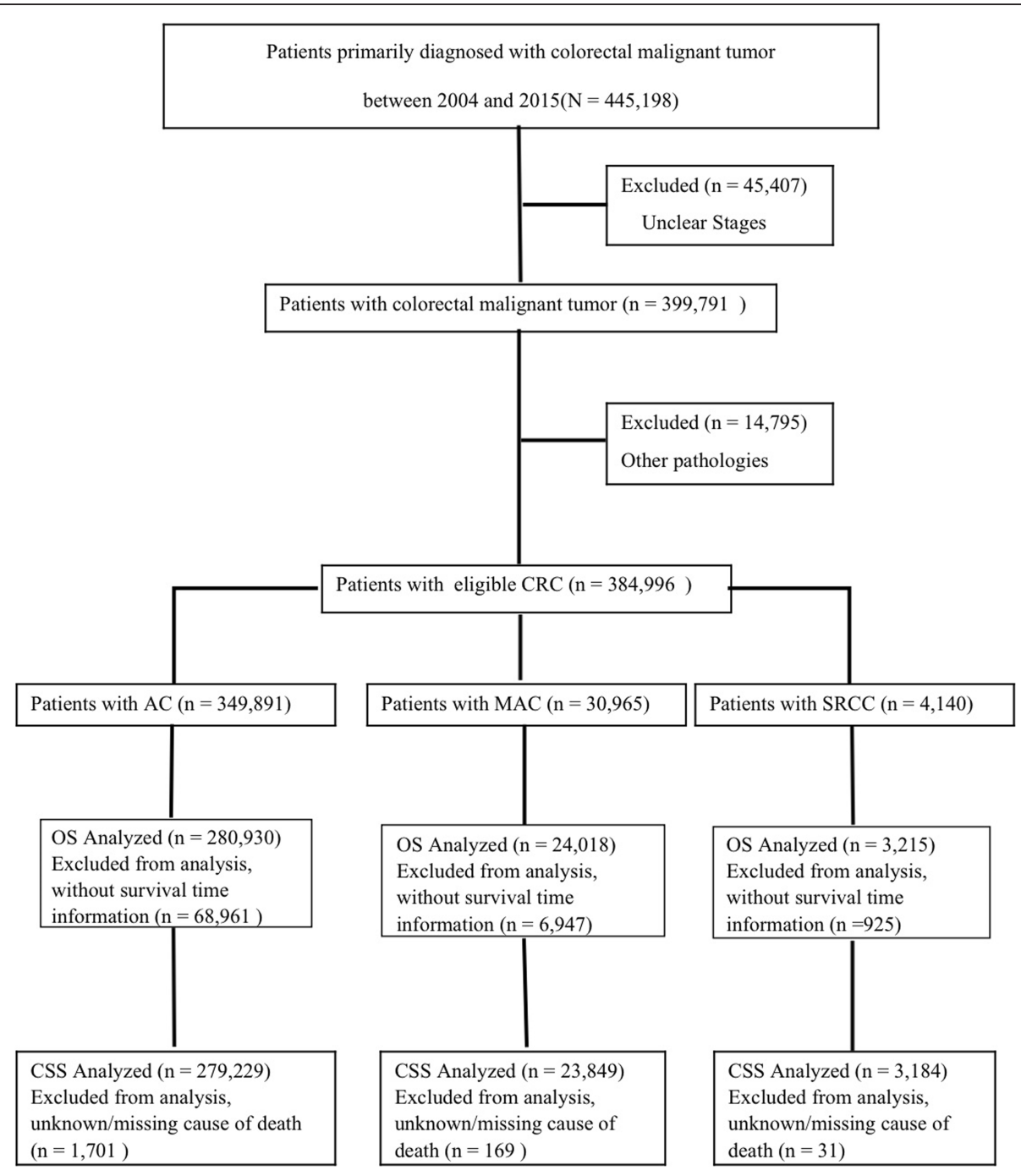

Fig. 1 Selection process for patients in the cohort study

correlation between pathological subtype and OS and CCS values at every stage. Cox regression analysis demonstrated that, compared with patients with $\mathrm{AC}$, those with MAC have poorer OS at every stage and poorer CSS at every stage except at stage II $(P<.05$, Tables 3 , 4). Patients with SRCC had poorer OS and CSS at every stage except stage $0(P<.05$, Tables 3,4$)$.

\section{Discussion}

Previous studies on the prognostic effects of different pathological subtypes in CRC have yielded conflicting results [8-11]. Therefore, to date, no clinical guidelines have yet been established for the different treatment methods for CRC of different pathological subtypes. For this reason, we conducted a populationbased study to analyze the prognoses of different pathological subtypes in patients with CRC. We found that MAC and SRCC were associated with various clinicopathological characteristics, such as a younger age, poorer grade of differentiation, easier metastasis, and advanced stage. These findings are consistent with those of previous researchers [2-4, 6, 7]. We also found that the prognoses statistically differed among patients with different pathological subtypes in terms of overall outcome; specifically, the pathological subtypes were correlated with the prognosis. Patients with AC had the best prognoses, whereas those with SRCC exhibited the poorest prognoses. The median OS and CSS of patients with SRCC were only 19 and 23 months, respectively. To explore the correlations between the prognoses and different pathological subtypes of patients with CRC at every stage, stagespecific Cox regression analysis was performed. We found that patients of different pathological subtypes were only minimally different, and no statistical difference at the early stages of the disease (i.e., no 
Table 1 Demographics and Clinical Characteristics of Patients with Colorectal Cancer in the Study

\begin{tabular}{|c|c|c|c|c|c|}
\hline \multirow[t]{2}{*}{ Variable } & \multirow{2}{*}{$\begin{array}{l}\text { All Patients } \\
(N=384,996)\end{array}$} & \multicolumn{3}{|l|}{ Tumor Histology } & \multirow[t]{2}{*}{$P$ value } \\
\hline & & $A C(N=349,891)$ & $\operatorname{MAC}(N=30,965)$ & $\operatorname{SRCC}(N=4140)$ & \\
\hline \multicolumn{5}{|l|}{ Sex, No. (\%) } & $<.001$ \\
\hline Male & 201,826 (52.4) & $184,408(52.7)$ & $15,221(49.2)$ & $2197(53.1)$ & \\
\hline Female & $183,170(47.6)$ & $165,483(47.3)$ & $15,744(50.8)$ & $1943(46.9)$ & \\
\hline \multicolumn{5}{|l|}{ Age, y, No. (\%) } & $<.001$ \\
\hline$\leq 44 y$ & $19,932(5.2)$ & $17,632(5.0)$ & $1819(5.9)$ & 481 (11.6) & \\
\hline $45-59 y$ & $91,886(23.9)$ & $84,785(24.2)$ & $6151(19.9)$ & $950(22.9)$ & \\
\hline $60-74 y$ & $141,249(36.7)$ & $129,226(36.9)$ & $10,646(34.4)$ & 1377 (33.3) & \\
\hline$\geq 75 y$ & $131,929(34.3)$ & 118,248 (33.8) & $12,349(39.9)$ & $1332(32.2)$ & \\
\hline \multicolumn{5}{|c|}{ Marital status, No. (\%) } & $<.001$ \\
\hline Unmarried & $205,102(53.3)$ & $186,964(53.4)$ & $15,941(51.5)$ & $2197(53.1)$ & \\
\hline Married & $160,284(41.6)$ & $144,728(41.4)$ & $13,778(44.5)$ & $1778(42.9)$ & \\
\hline Unknown & $19,610(5.1)$ & $18,199(5.2)$ & $1246(4.0)$ & $165(4.0)$ & \\
\hline \multicolumn{5}{|l|}{ T, No. (\%) } & $<.001$ \\
\hline T0 & $567(0.1)$ & $499(0.1)$ & $60(0.2)$ & $8(0.2)$ & \\
\hline Tis & $14,784(3.8)$ & $14,650(4.2)$ & $108(0.3)$ & $26(0.6)$ & \\
\hline $\mathrm{T} 1$ & $67,426(17.5)$ & 65,451 (18.7) & $1692(5.5)$ & $283(6.8)$ & \\
\hline $\mathrm{T} 2$ & $50,455(13.1)$ & $46,734(13.4)$ & $3550(11.5)$ & $171(4.1)$ & \\
\hline T3 & $180,679(46.9)$ & $161,305(46.1)$ & $17,606(56.9)$ & $1768(42.7)$ & \\
\hline T4 & $52,617(13.7)$ & $44,210(12.6)$ & $6884(22.2)$ & $1523(36.8)$ & \\
\hline Tx & $18,468(4.8)$ & $17,042(4.9)$ & $1065(3.4)$ & $361(8.7)$ & \\
\hline \multicolumn{5}{|l|}{ N, No. (\%) } & $<.001$ \\
\hline NO & $230,313(59.8)$ & $212,807(60.8)$ & $16,251(52.5)$ & 1255 (30.3) & \\
\hline N1 & 89,719 (23.3) & $80,920(23.1)$ & 7874 (25.4) & $925(22.3)$ & \\
\hline N2 & $53,294(13.8)$ & 45,509 (13.0) & 6087 (19.7) & $1698(41.0)$ & \\
\hline NX & $11,670(3.0)$ & 10,655 (3.0) & 753 (2.4) & $262(6.3)$ & \\
\hline \multicolumn{5}{|l|}{ M, No. (\%) } & $<.001$ \\
\hline MO & $310,099(80.5)$ & 282,887 (80.9) & $24,669(79.7)$ & $2543(61.4)$ & \\
\hline M1 & 74,512 (19.4) & $66,626(19.0)$ & $6291(20.3)$ & 1595 (38.5) & \\
\hline MX & $385(0.1)$ & $378(0.1)$ & $5(0.0)$ & $2(0.0)$ & \\
\hline \multicolumn{5}{|l|}{ Stage, No. (\%) } & $<.001$ \\
\hline 0 & $14,784(3.8)$ & $14,650(4.2)$ & $108(0.3)$ & $26(0.6)$ & \\
\hline I & $95,327(24.8)$ & $91,062(26.0)$ & 4007 (12.9) & $258(6.2)$ & \\
\hline$\|$ & $98,990(25.7)$ & $87,722(25.1)$ & $10,643(34.4)$ & $625(15.1)$ & \\
\hline III & $101,383(26.3)$ & $89,831(25.7)$ & 9916 (32.0) & 1636 (39.5) & \\
\hline IV & $74,512(19.4)$ & $66,626(19.0)$ & $6291(20.3)$ & 1595 (38.5) & \\
\hline \multicolumn{5}{|l|}{ Grade, No. (\%) } & $<.001$ \\
\hline 1 & $32,258(8.4)$ & 29,373 (8.4) & 2861 (9.2) & $24(0.6)$ & \\
\hline$\|$ & $244,735(63.6)$ & $226,222(64.7)$ & $18,318(59.2)$ & $195(4.7)$ & \\
\hline III & $58,637(15.2)$ & 50,223 (14.4) & $5603(18.1)$ & $2811(67.9)$ & \\
\hline IV & 7371 (1.9) & $6053(1.7)$ & $853(2.8)$ & 465 (11.2) & \\
\hline Unknown & 41,995 (10.9) & $38,020(10.9)$ & 3330 (10.8) & 645 (15.6) & \\
\hline
\end{tabular}


Table 2 Factors Associated with the Survival of Patients with CRC

\begin{tabular}{|c|c|c|c|c|c|c|}
\hline \multirow[t]{3}{*}{ Covariate } & \multicolumn{3}{|c|}{ 5-y Overall Survival } & \multicolumn{3}{|c|}{ 5-y Cancer-Specific Survival } \\
\hline & \multirow{2}{*}{$\begin{array}{l}\text { Total No. (OS, } \\
\%)\end{array}$} & \multicolumn{2}{|l|}{ Logistic Analysis } & \multirow{2}{*}{$\begin{array}{l}\text { Total No. (CSS, } \\
\%)\end{array}$} & \multicolumn{2}{|l|}{ Logistic Analysis } \\
\hline & & Hazard Ratio (95\% Cl) & $\begin{array}{l}P \\
\text { Value }\end{array}$ & & Hazard Ratio $(95 \%$ Cl) & $\begin{array}{l}P \\
\text { Value }\end{array}$ \\
\hline \multicolumn{7}{|l|}{ Sex } \\
\hline Male & $161,545(56.7)$ & 1 [Reference] & & $160,455(66.6)$ & 1 [Reference] & \\
\hline Female & $146,618(57.6)$ & $0.964(0.950-0.978)$ & $<.001$ & $145,807(67.2)$ & $0.973(0.959-0.988)$ & $<.001$ \\
\hline \multicolumn{7}{|l|}{ Age, y } \\
\hline$\leq 44$ y & $18,591(65.2)$ & 1 [Reference] & & $18,463(67.1)$ & 1 [Reference] & \\
\hline $45-59 y$ & $82,523(67.1)$ & $0.919(0.888-0.950)$ & $<.001$ & $82,076(70.6)$ & $0.849(0.821-0.879)$ & $<.001$ \\
\hline $60-74 y$ & $114,178(61.8)$ & $1.158(1.121-1.196)$ & $<.001$ & $113,505(69.7)$ & $0.887(0.858-0.917)$ & $<.001$ \\
\hline$\geq 75 y$ & $92,871(41.5)$ & $2.641(2.556-2.729)$ & $<.001$ & $92,218(60.1)$ & $1.354(1.310-1.400)$ & $<.001$ \\
\hline \multicolumn{7}{|l|}{ Marital status } \\
\hline Married & $165,165(62.8)$ & 1 [Reference] & & $164,265(70.8)$ & 1 [Reference] & \\
\hline Unmarried & $127,587(49.1)$ & $1.750(1.724-1.776)$ & $<.001$ & $126,716(61.1)$ & $1.544(1.520-1.568)$ & $<.001$ \\
\hline Unknown & $15,411(61.7)$ & $1.048(1.013-1.084)$ & .007 & $15,281(72.1)$ & $0.938(0.904-0.974)$ & $<.001$ \\
\hline 0 & $11,192(80.0)$ & 1 [Reference] & & $11,142(93.6)$ & 1 [Reference] & \\
\hline 1 & $72,764(77.7)$ & $1.148(1.093-1.206)$ & $<.001$ & $72,462(91.4)$ & $1.376(1.270-1.491)$ & $<.001$ \\
\hline$\|$ & $78,593(68.3)$ & $1.857(1.768-1.949)$ & $<.001$ & $78,201(81.6)$ & $3.298(3.050-3.565)$ & $<.001$ \\
\hline III & $83,499(59.4)$ & $2.734(2.605-2.869)$ & $<.001$ & $83,024(67.9)$ & $6.914(6.400-7.469)$ & $<.001$ \\
\hline IV & $62,115(10.6)$ & $\begin{array}{l}33.736(31.998- \\
35.568)\end{array}$ & $<.001$ & $61,433(12.1)$ & $\begin{array}{l}106.242(98.109- \\
115.050)\end{array}$ & $<.001$ \\
\hline \multicolumn{7}{|l|}{ Histology } \\
\hline$A C$ & $280,930(58.0)$ & 1 [Reference] & & $279,229(67.8)$ & 1 [Reference] & \\
\hline MAC & $24,018(50.7)$ & $1.343(1.308-1.379)$ & $<.001$ & $23,849(60.9)$ & $1.352(1.316-1.389)$ & $<.001$ \\
\hline SRCC & 3215 (26.8) & $3.772(3.487-4.079)$ & $<.001$ & $3184(32.5)$ & $4.373(4.059-4.712)$ & $<.001$ \\
\hline \multicolumn{7}{|l|}{ Grade } \\
\hline Grade I & $25,618(69.4)$ & 1 [Reference] & & $25,478(81.1)$ & 1 [Reference] & \\
\hline Grade ॥ & $197,250(60.7)$ & $1.468(1.428-1.510)$ & $<.001$ & $196,101(70.9)$ & $1.761(1.704-1.820)$ & $<.001$ \\
\hline Grade III & $46,599(44.4)$ & $2.840(2.750-2.933)$ & $<.001$ & $46,277(52.7)$ & 3.851 (3.714-3.994) & $<.001$ \\
\hline Grade IV & $5770(44.7)$ & $2.806(2.647-2.974)$ & $<.001$ & $5741(53.3)$ & $3.760(3.539-3.995)$ & $<.001$ \\
\hline Unknown & $32,926(46.2)$ & $2.641(2.552-2.733)$ & $<.001$ & $32,665(54.6)$ & $3.568(3.434-3.707)$ & $<.001$ \\
\hline
\end{tabular}

lymph node metastasis) was observed. Thus, patients with SRCC had OS and CSS similar to those with AC at stage $0(P=0.895$ and $P=0.123$, respectively $)$, and patients with MAC had CSS similar to those with AC at stage II $(P=0.604)$. A small number of recent studies demonstrated that SRCC does not negatively affect survival in stage I and II colorectal tumors [14].

In contrast to findings among early-stage CRC, patients with MAC and SRCC had poor OS and CSS in advanced CRC (stages III and IV). The key pathological

Table 3 Histology Correlated With Overall Survival among 308,163 Patients with Colorectal Cancer

\begin{tabular}{|c|c|c|c|c|c|c|c|}
\hline \multirow[t]{2}{*}{ Stage } & \multicolumn{3}{|l|}{ Histology } & \multicolumn{4}{|l|}{ Cox Regression } \\
\hline & $\begin{array}{l}\text { AC } \\
\text { Total No. (5-y OS, \%) }\end{array}$ & $\begin{array}{l}\text { MAC } \\
\text { Total No. (5-y OS, \%) }\end{array}$ & $\begin{array}{l}\text { SRCC } \\
\text { Total No. (5-y OS, \%) }\end{array}$ & MAC vs. AC HR (95) Cl\% & $P$ Value & $\begin{array}{l}\text { SRCC vs. AC } \\
\text { HR (95) Cl\% }\end{array}$ & P Value \\
\hline $0-\mathrm{IV}$ & $280,930(58.0)$ & $24,018(50.7)$ & $3215(26.8)$ & $1.238(1.213-1.263)$ & $<.001$ & $1.592(1.558-1.627)$ & $<.001$ \\
\hline 0 & $11,113(80.1)$ & $66(69.1)$ & $13(83.1)$ & $1.656(1.054-2.602)$ & .029 & $0.954(0.477-1.909)$ & .895 \\
\hline । & $69,751(77.9)$ & $2848(72.7)$ & $165(63.4)$ & $1.268(1.172-1.371)$ & $<.001$ & $1.387(1.207-1.593)$ & $<.001$ \\
\hline$\|$ & $70,050(68.6)$ & $8075(66.6)$ & $468(56.0)$ & $1.072(1.029-1.122)$ & .001 & $1.279(1.188-1.377)$ & $<.001$ \\
\hline III & $74,341(60.6)$ & $7863(52.6)$ & 1295 (34.6) & $1.297(1.250-346)$ & $<.001$ & $1.519(1.464-1.576)$ & $<.001$ \\
\hline IV & $55,675(10.8)$ & $5166(10.0)$ & $1274(2.5)$ & $1.053(1.020-1.087)$ & .001 & $1.245(1.208-1.282)$ & $<.001$ \\
\hline
\end{tabular}


Table 4 Histology Correlated With Cause-Specific Survival among 306,262 Patients with Colorectal Cancer

\begin{tabular}{|c|c|c|c|c|c|c|c|}
\hline \multirow[t]{2}{*}{ Stage } & \multicolumn{3}{|l|}{ Histology } & \multicolumn{4}{|l|}{ Cox Regression } \\
\hline & $\begin{array}{l}\text { AC } \\
\text { Total No. (5-y CSS, \%) }\end{array}$ & $\begin{array}{l}\text { MAC } \\
\text { Total No. (5-y CSS, \%) }\end{array}$ & $\begin{array}{l}\text { SRCC } \\
\text { Total No. (5-y CSS, \%) }\end{array}$ & MAC vs. AC HR (95) Cl\% & P Value & $\begin{array}{l}\text { SRCC vs. AC } \\
\text { HR (95) Cl\% }\end{array}$ & P Value \\
\hline 0-IV & $279,229(67.8)$ & $23,849(60.9)$ & $3184(32.5)$ & $1.271(1.242-1.302)$ & $<.001$ & $1.724(1.685-1.765)$ & $<.001$ \\
\hline 0 & $11,064(93.7)$ & $65(83.4)$ & $13(83.1)$ & $2.592(1.342-5.007)$ & .005 & $1.726(0.862-3.455)$ & .123 \\
\hline | & 69,464 (91.4) & $2833(90.1)$ & $165(74.6)$ & $1.174(1.027-1.341)$ & .018 & $1.828(1.540-2.169)$ & $<.001$ \\
\hline$\|$ & $69,705(81.7)$ & 8031 (81.6) & $465(70.3)$ & $1.016(0.957-1.079)$ & .604 & $1.372(1.251-1.506)$ & .011 \\
\hline III & $73,923(69.1)$ & $7816(61.1)$ & $1285(41.1)$ & $1.356(1.300-1.415)$ & $<.001$ & $1.630(1.565-1.697)$ & $<.001$ \\
\hline IV & $55,073(12.4)$ & $5104(11.4)$ & $1256(3.2)$ & $2.218(2.146-2.293)$ & $<.001$ & $1.734(1.681-1.788)$ & $<.001$ \\
\hline
\end{tabular}

difference among the three subtypes is that both MAC and SRCC produce large amounts of mucin. The World Health Organization defines MAC as a carcinoma conformed by $>50 \%$ of extracellular mucin pools that contain malignant epithelial or.

individual tumor cells including signet-ring cells (SRC); it defines SRCC as a carcinoma conformed by > $50 \%$ of SRC. A unique pathologic feature of SRCC is that SRC have intracytoplasmic mucin vacuoles that displace the nuclei to the periphery.

Previous researchers have demonstrated the importance of mucin in prognosis $[15,16]$. One study enrolled patients with CRC of different stages and receiving adjuvant chemotherapy via the FOLFOX regimen [15]. Another recent study enrolled only patients with stage III
CRC who were also receiving adjuvant chemotherapy via the FOLFOX regimen [16]. The results of these studies showed that patients with MAC have poorer prognoses than those without mucin. This research reveals that patients with MAC have significantly poorer prognoses than those with AC. The poor prognoses for patients with MAC and SRCC may be due to aggressive infiltrating tumor growth, which promotes higher rates of lymphovascular invasion [17].

We found that patients with MAC and SRCC experienced lymph node metastasis more frequently than those with MAC (47.5 and $69.7 \%$ vs. $39.2 \%$ ). Other studies investigating the molecular characteristics of SRCC have demonstrated that most SRCC cases feature variable molecular alterations, including highly microsatellite

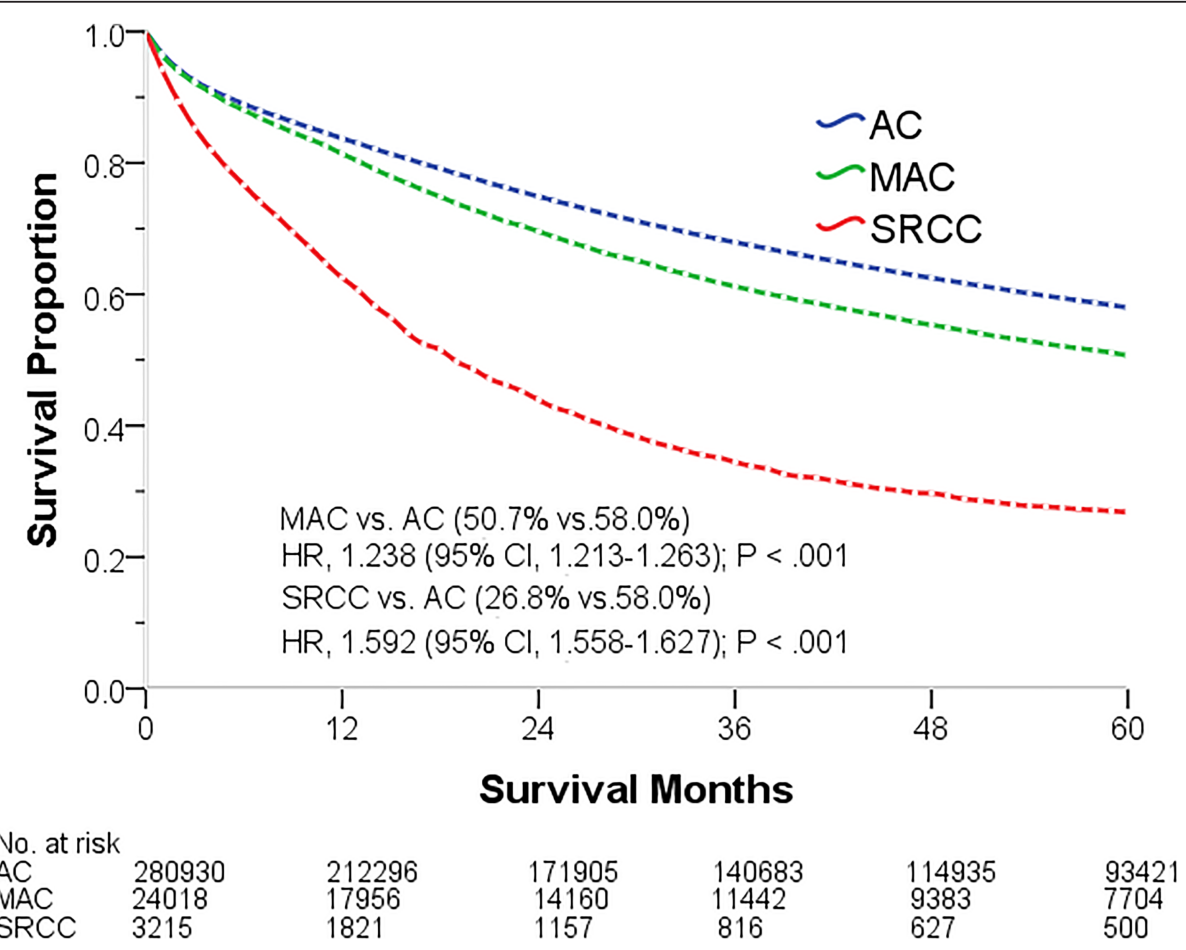

Fig. 2 Five-year overall survival of patients of different pathological subtypes 


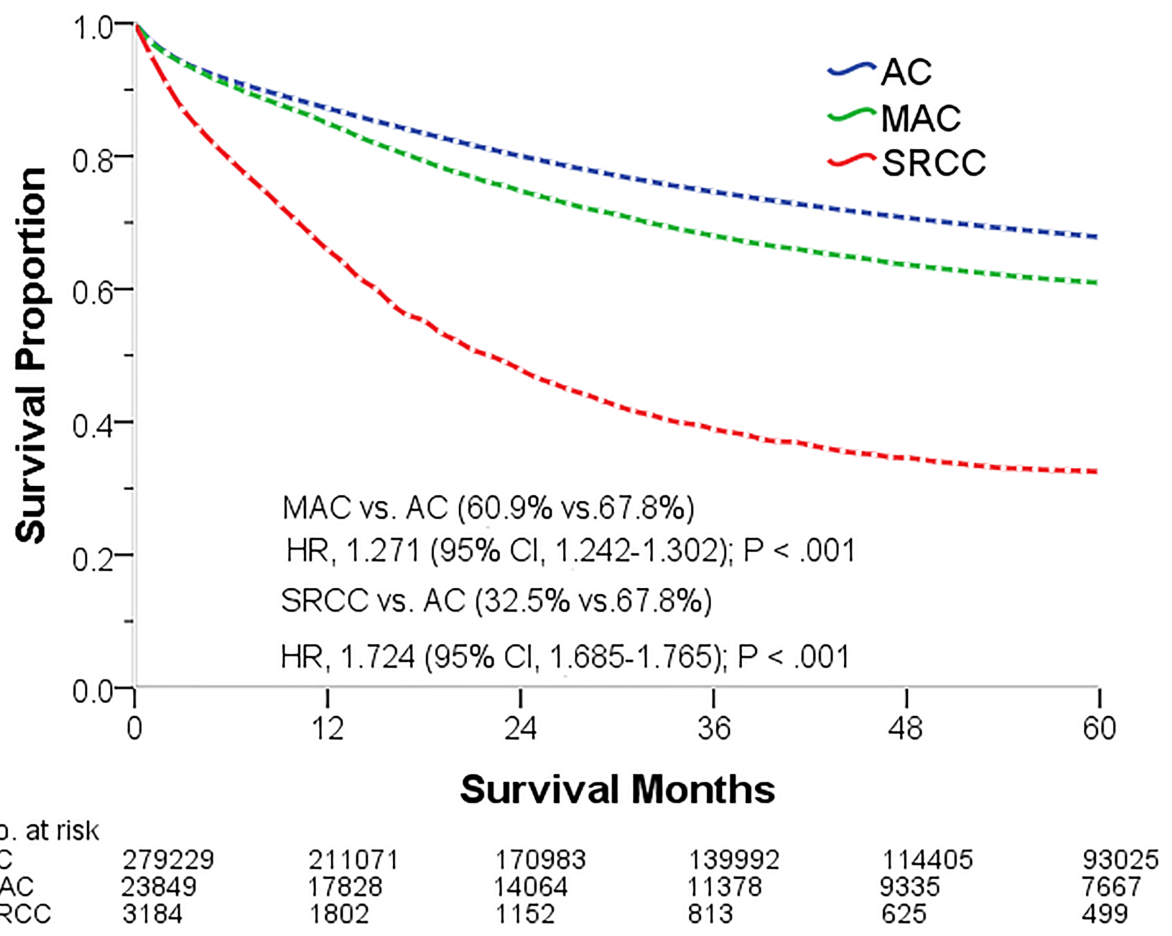

Fig. 3 Five-year cause-specific survival of patients of different pathological subtypes

instability, a high CpG island methylator phenotype, and high frequency of BRAF V600E mutation [18-22]. The poor prognoses of patients with SRCC may also be explained by the low suitability of the existing standard treatment approach for these patients [23]. Improving the treatment approach requires special schemes based on the genetic background of the disease.

\section{Limitations and strengths}

To the best of our knowledge, this work is the most comprehensive study exploring the correlation between different pathological subtypes and prognoses of patients with CRC. This study presents a number of strengths. First, our data come from naturally registered patients, who are highly popular, which means our data are credible. Second, our data spanned a period of over 10 years and included more than 384,000 patients. Larger sample sizes tend to be more reliable than smaller ones. Third, we used different analytical methods to prove the consistency and reliability of this results. Nevertheless, this research also presents a number of limitations. In particular, data on treatment approaches, performance status, and molecular features (e.g., MSI status and BRAF mutation) were unavailable in the SEER database.

\section{Conclusions}

This population-based cohort study on patients with CRC of different pathological subtypes provided compelling evidence that different pathological subtypes are only minimally different at early stages. However, they were significantly different prognosis, and patients with MAC and SRCC have poorer OS and CCS, which are mainly in advanced CRC (stages III and IV). Therefore, different treatment strategies specific for a particular histological subset should be applied in advanced CRC.

\section{Abbreviations \\ AC: Adenocarcinoma; CRC: Colorectal cancer; CSS: Cause-specific survival; ICDO: International Classification of Diseases for Oncology; MAC: Mucinous adenocarcinoma; NAACCR: North American Association of Central Cancer Registries; OS: Overall Survival; SEER: Surveillance, epidemiology, and end results; SRCC: Signet ring cell carcinoma}

\section{Acknowledgments}

Not applicable.

\section{Authors' contributions}

SL had full access to all of the data in the study and takes responsibility for the integrity of the data and the accuracy of the study design; collection, analysis, and interpretation of data; final approval of the version to be published and obtained funding. XW performed acquisition, analysis, or interpretation of data and obtained funding. HL offered technical and material support and performed statistical analysis. All authors have read and approved the manuscript in its current state.

\section{Funding}

This work was supported by a grant from Natural Science Foundation of Zhejiang Province of China (LY18H030008), funds from the Wenzhou Science and Technology Planning Project (Y20180085), and a grant from Wenzhou Municipal Science and Technology Commission Major Projects Funds (Y20150029). The founders had no role in study design, data collection and analysis, decision to publish, or preparation of the manuscript. 


\section{Availability of data and materials}

The data used and/or analyzed during the study are available from the corresponding author on reasonable request.

\section{Ethics approval and consent to participate}

As the data used were from SEER dataset (public), ethics approval and consent to participate could be checked in SEER.

\section{Consent for publication}

Not Applicable.

\section{Competing interests}

The authors declare that they have no competing interests.

\section{Author details}

'Department of gastroenterology, the First Affiliated Hospital of Wenzhou Medical University, Wenzhou, Zhejiang, People's Republic of China. 2Department of Central Laboratory, the First Affiliated Hospital of Wenzhou Medical University, Wenzhou, Zhejiang, People's Republic of China. ${ }^{3}$ Department of Colorectal Surgery, the First Affiliated Hospital of Wenzhou Medical University, Wenzhou, Zhejiang, People's Republic of China.

Received: 4 June 2019 Accepted: 20 September 2019

Published online: 10 October 2019

\section{References}

1. Ferlay J, Soerjomataram I, Dikshit R, Eser S, Mathers C, Rebelo M, et al. Cancer incidence and mortality worldwide: sources, methods and major patterns in GLOBOCAN 2012. Int J Cancer. 2015;136(5):E359-86.

2. Liang Z, Yan D, Li G, Cheng H. Clinical analysis of primary colorectal signetring cell carcinoma. Clin Colorectal Cancer. 2018;17(1):e39-44. https://doi. org/10.1016/j.clcc.2017.06.010 Epub 2017 Jul 8

3. Hyngstrom JR, Hu CY, Xing Y, You YN, Feig BW, Skibber JM, et al. Clinicopathology and outcomes for mucinous and signet ring colorectal adenocarcinoma: analysis from the national Cancer data base. Ann Surg Oncol. 2012;19(9):2814-21.

4. Gao P, Song YX, Xu YY, Sun Z, Sun JX, Xu HM, et al. Does the prognosis of colorectal mucinous carcinoma depend upon the primary tumour site? Results from two independent databases. Histopathology. 2013;63(5):603-15.

5. Mizushima T, Nomura M, Fujii M, Akamatsu $H$, Mizuno H, Tominaga $H$, et al. Primary colorectal signet ring cell carcinoma: Clinicopathological features and postoperative survival. Surg Today. 2010;40(3):234-8.

6. Yamaguchi T, Taniguchi H, Fujita S, Sekine S, Yamamoto S, Akasu T, et al. Clinicopathological characteristics and prognostic factors of advanced colorectal mucinous adenocarcinoma. Histopathology. 2012;61 (2):162-9.

7. Gopalan V, Smith RA, Ho YH, Lam AKY. Signet-ring cell carcinoma of colorectum-current perspectives and molecular biology. Int J Color Dis. 2011:26(2):127-33.

8. Consorti F, Lorenzotti A, Midiri G, Di Paola M. Prognostic significance of mucinous carcinoma of colon and rectum: a prospective case-control study. J Surg Oncol. 2000;73(2):70-4.

9. Verhulst J, Ferdinande L, Demetter P, Ceelen W. Mucinous subtype as prognostic factor in colorectal cancer: a systematic review and metaanalysis. J Clin Pathol. 2012;65(5):381-8.

10. Green JB, Timmcke AE, Mitchell WT. Hicks TC, Gathright JB, Ray JE. Mucinous carcinoma-just another Colon Cancer. Dis Colon Rectum. 1993;36(1):49-54.

11. Farhat MH, Barada KA, Tawil AN, Itani DM, Hatoum HA, Shamseddine Al. Effect of mucin production on survival in colorectal cancer: a case-control study. World J Gastroenterol. 2008:14(45):6981-5.

12. Wingo PA, Jamison PM, Hiatt RA, Weir HK, Gargiullo PM, Hutton M, et al. Building the infrastructure for nationwide cancer surveillance and control-a comparison between the National Program of Cancer registries (NPCR) and the surveillance, epidemiology, and end results (SEER) program (United States). Cancer Causes Control. 2003;14(2):175-93.

13. Fritz A, Percy C, Jack A, Shanmugaratnam K, Sobin L, Parkin DM, et al. International Classification of Diseases for Oncology. 3rd ed. Geneva: World Health Organization; 2000.

14. Ackermann CJ, Guller U, Jochum W, Schmied BM, Warschkow R. The prognostic value of signet ring cell histology in stage $1 / / l$ colon cancer-a population-based, propensity score-matched analysis. Int J Color Dis. 2018 https://doi.org/10.1007/s00384-018-3096-5 [Epub ahead of print].
15. Maisano R, Azzarello D, Maisano M, Mafodda A, Bottari M, Egitto G, et al. Mucinous histology of colon cancer predicts poor outcomes with FOLFOX regimen in metastatic colon cancer. J Chemotherapy. 2012;24(4):212-6.

16. Kim SH, Shin SJ, Lee KY, Kim H, Kim TI, Kang DR, et al. Prognostic value of mucinous histology depends on microsatellite instability status in patients with stage III Colon Cancer treated with adjuvant FOLFOX chemotherapy: a retrospective cohort study. Ann Surg Oncol. 2013;20(11):3407-13.

17. Yun SO, Cho YB, Lee WY, Kim HC, Yun SH, Park YA, et al. Clinical significance of signet-ring-cell colorectal Cancer as a prognostic factor. Ann Coloproctol. 2017;33(6):232-8.

18. Inamura K, Yamauchi M, Nishihara R, Kim SA, Mima K, Sukawa Y, et al. Prognostic significance and molecular features of signetring cell and mucinous components in colorectal carcinoma. Ann Surg Oncol. 2015;22(4): 1226-35.

19. Kakar S, Deng G, Sahai V, Matsuzaki K, Tanaka H, Miura S, et al. Clinicopathologic characteristics, CpG island methylator phenotype, and BRAF mutations in microsatellite-stable colorectal cancers without chromosomal instability. Arch Pathol Lab Med. 2008;132(6):958-64.

20. Kakar S, Deng GR, Smyrk TC, Cun L, Sahai V, Kim YS. Loss of heterozygosity, aberrant methylation, BRAF mutation and KRAS mutation in colorectal signet ring cell carcinoma. Mod Pathol. 2012;25(7):1040-7.

21. Kakar S, Smyrk TC. Signet ring cell carcinoma of the colorectum: correlations between microsatellite instability, clinicopathologic features and survival. Mod Pathol. 2005;18(2):244-9.

22. Alvi MA, Loughrey MB, Dunne P, McQuaid S, Turkington R, Fuchs MA, et al. Molecular profiling of signet ring cell colorectal cancer provides a strong rationale for genomic targeted and immune checkpoint inhibitor therapies. Br J Cancer. 2017;117(2):203-9.

23. Fu J, Wu L, Jiang M, Tan Y, Li D, Chen F, et al. Signet ring cell carcinoma of Resectable metastatic colorectal Cancer has rare surgical value. J Surg Oncol. 2016:114(8):1004-8.

\section{Publisher's Note}

Springer Nature remains neutral with regard to jurisdictional claims in published maps and institutional affiliations.

Ready to submit your research? Choose BMC and benefit from:

- fast, convenient online submission

- thorough peer review by experienced researchers in your field

- rapid publication on acceptance

- support for research data, including large and complex data types

- gold Open Access which fosters wider collaboration and increased citations

- maximum visibility for your research: over $100 \mathrm{M}$ website views per year

At $\mathrm{BMC}$, research is always in progress.

Learn more biomedcentral.com/submission 